\title{
PP013 - Maxadilan (MAX) - Proteína salivar de Lutzomyia longipalpis: detecção de anticorpos antiMAX em leishmaniose tegumentar americana (LTA) e expressão gênica e protéica de MAX em Lutzomyia neivai" Maxadilan (MAX) - Salivary protein of Lutzomyia longipalpis: Detection of antibodies anti-MAX in American tegumentar leishmaniasis (ATL), and genetic and protein expression of MAX in Lutzomyia neivai"
}

\author{
Juliana Machado Aires ${ }^{1}$ \\ José Fernando de C. Figueiredo ${ }^{4}$ \\ Maria Fernanda Chociay ${ }^{2}$
}

Margarida M. P. Nascimento ${ }^{3}$

Resumo: FUNDAMENTOS - A proteína MAX, componente salivar de Lutzomyia longipalpis, vetor do calazar ou leishmaniose sistêmica, tem sido empregada como vacina para leishmaniose tegumentar experimental, com funções de vasodilatação e imunomodulação.

OBjetivos - Detectar anticorpos séricos antiMAX em pacientes com LTA e verificar a expressão de MAX em L. neivai, vetor da LTA na região em estudo.

MÉTodos - Anticorpos antiMAX foram detectados por Elisa em soro de 42 pacientes com LTA e 63 controles. A extração de proteínas e de DNA de L. longipalpis (controle positivo) e de L. neivai foi realizada pelo método Trizol e seguida pela detecção de proteínas por eletroforese e pela expressão gênica de MAX por PCR-RFLP (polymerase chain reaction-restriction fragment length polymorphism) com as enzimas Hha I e Rsa I.

RESULTADOS - Títulos maiores de anticorpos antiMAX foram observados na LTA $(p=0,0132)$. A eletroforese de proteínas mostrou frações semelhantes para L. longipalpis e $L$. neivai, tendo-se observado para ambos fração protéica de peso molecular similar à proteína MAX. A expressão gênica de MAX em L. longipalpis e L. neivai foi confirmada por PCR-RFLP. CONCLUSÕES - A presença de antiMAX nos grupos em estudo tornou imprescindível a pesquisa de MAX no vetor de LTA da região, tendo sido registrada pela primeira vez expressão protéica e gênica de MAX em $L$. neivai. Detecção de antiMAX em controles confirma exposição a picadas de flebótomos. Títulos de anticorpos antiMAX maiores na LTA sugerem exposição prévia e natural à picada e, conseqüentemente, à proteína MAX, não protegendo da doença e desfavorecendo seu emprego em vacinação. Palavras-chave: Leishmaniose tegumentar americana

\begin{abstract}
BACKGROUND - The protein MAX, salivary component of Lutzomyia longipalpis, vector of calazar or systemic leishmaniasis, has been used as vaccine for experimental tegumentar leishmaniasis, which vasodilatory and immunomodulatory functions are described.

OBJECTIVE - Our purpose was to detect antibodies antiMAX in sera samples from patients with ATL and to verify the genetic and protein expression of MAX in L. neivai, pblebotomy vector of ATL in the area of study.

METHODS - Antibodies antiMAX were detected by ELISA in sera from 42 patients with ATL and 63 controls. The extraction of proteins and of DNA from L. longipalpis (positive control) and L. neivai was accomplished by the method Trizol, following for the detection of proteins by electrophoresis, and genetic expression of MAX by PCR-RFLP (polymerase chain reaction-restriction fragment length polymorphism) with the enzymes Hha I and Rsa I.

RESULTS - Increased titles of antibodies antiMAX were observed in ATL, compared to controls $(p=0,0132)$. Electrophoreses of proteins showed similar fractions for L. longipalpis and L. neivai, and for both a protein fraction with molecular weight similarity to MAX was observed. The genetic expression of MAX in L. longipalpis and L. neivai was confirmed by PCR-RFLP. CONCLUSIONS - The description of antibodies antiMAX in ATL patients and controls turned indispensable the research of MAX in the phlebotomy vector of ATL in the area of study. For the first time, it was registered protein and genetic expression of MAX in L. neivai. The antiMAX detection in controls confirms the previous exposition to prick of phlebotomies. Increased titles of antibodies antiMAX in ATL patients suggest previous and natural exposition to the bite and, consequently, to the protein MAX, not protecting them of disease and discouraging its employment in vaccination. Keywords: American tegumentar leishmaniasis
\end{abstract}

* Trabalho realizado no Laboratório de Biologia Molecular da Divisão de Dermatologia e ${ }^{+}$Laboratório de Sorologia da Divisão de Moléstias Infecciosas, Departamento de Clínica Médica, Faculdade de Medicina de Ribeirão Preto, Universidade de São Paulo - São Paulo (SP), Brasil

Aluna de Pós-Graduação (Doutorado Direto), bolsista Capes (2002-2004), Programa Clínica Médica, Faculdade de Medicina de Ribeirão Preto, USP São Paulo (SP), Brasil

Aluna de Pós-Graduação (Doutorado), bolsista Capes, Programa Clínica Médica, Área Investigação Biomédica, Faculdade de Medicina de Ribeirão Preto, USP - São Paulo (SP), Brasil

Biomédica, Laboratório de Sorologia, Hospital das Clínicas, Faculdade de Medicina de Ribeirão Preto, USP - São Paulo (SP), Brasil

Professor Doutor, Divisão de Moléstias Infecciosas, Departamento de Clínica Médica, Faculdade de Medicina de Ribeirão Preto, USP - São Paulo (SP), Brasil

Professora-associada, Divisão de Dermatologia, Departamento de Clínica Médica, Faculdade de Medicina de Ribeirão Preto, USP - São Paulo (SP), Brasil 


\section{INTRODUÇÃO}

As leishmanioses são zoonoses que afetam a pele, mucosas ou vísceras, resultantes do parasitismo dos macrófagos pelo protozoário do gênero Leishmania, inoculado no organismo pela picada de um inseto flebótomo. ${ }^{1} \mathrm{Na}$ região de Ribeirão Preto, há registro de casos autóctones de leishmaniose tegumentar americana (LTA), sendo Leishmania Viannia braziliensis e Leishmania Leishmania amazonensis as espécies implicadas nas formas cutânea e mucosa. ${ }^{2}$ Quanto aos vetores, tem-se a informação verbal que são encontrados nesta região: Lutzomyia intermedia - Lutz \& Neiva, 1912 (SUCEN, Araraquara) e Lutzomyia neivai - Pinto, 1926 (SUCEN, Mogi Guaçu). Até 1996, ambos eram considerados a mesma espécie.

Maxadilan (MAX) é um peptídeo de $7 \mathrm{kDa}$, vasodilatador potente e com propriedades imunomodulatórias, presente na glândula salivar de Lutzomyia longipalpis. ${ }^{3}$ Lerner e Shoemarker ${ }^{4}$ clonaram e produziram MAX recombinante em Escherichia coli com as mesmas propriedades da proteína salivar. Sua atividade vasodilatadora é 500 vezes maior que a do CGRP (calcitonin gene-related peptide), até então o mais potente vasodilatador conhecido. ${ }^{4,5}$ MAX é um agonista específico dos receptores pituitários tipo 1 do peptídeo ativador da adenil-ciclase (Pacap -pituitary adenylate cyclase activating peptide), um peptídeo endógeno encontrado nos mamíferos. Surpreendentemente, o peptídeo salivar não apresenta qualquer seqüência homóloga ao Pacap, apesar de se ligar no mesmo sítio em seu receptor tipo 1 e promover sua ativação. ${ }^{6}$

Várias publicações sobre sua capacidade de imunomodulação surgiram e implicaram-no como fator de promoção da infecção, desviando a resposta Th1 para Th2 e favorecendo a evolução da doença. ${ }^{7.9}$ Esses mecanismos (vasodilatação e imunomodulação) promovem campo perfeito para a injeção do parasito em seu hospedeiro, com resposta inflamatória mínima, por picada e salivação do vetor. Isso talvez possa explicar por que os artrópodes são vetores extremamente eficientes na transmissão de várias doenças.

Diante das evidências de imunomodulação promovida pelo MAX, ele tem sido empregado em vacina experimental para leishmaniose. ${ }^{10}$ Como sua expressão se limita a L. longipalpis, vetor do calazar, teve-se por objetivos: 1) detectar antiMAX em soro de pacientes com LTA e 2) verificar a expressão de MAX em $L$. neivai, vetor da LTA na região estudada.

\section{MATERIAL E MÉTODOS}

Realizou-se levantamento dos prontuários de pacientes com diagnóstico confirmado de LTA, atendi- dos no Hospital das Clínicas da Faculdade de Medicina de Ribeirão Preto da Universidade de São Paulo (HCFMRP-USP), no período de 1999 a junho de 2004, após aprovação pelo Comitê de Ética em Pesquisa (Processo HCRP n. 5.886/2002), tendo como critérios de inclusão no mínimo dois dos seguintes itens:

1. diagnóstico clinicoepidemiológico compatível com LTA; 2. intradermorreação de Montenegro (IRM) positiva; 3. exame histopatológico de amostra de pele ou de mucosa compatível com LTA, incluída a descrição da presença de parasitos sugestivos do gênero Leishmania;

4. reação sorológica de imunofluorescência indireta (RIFI) para LTA positiva;

5. PCR para pesquisa de leishmania realizada em amostras de pele ou de mucosa positiva.

Foram selecionados 42 pacientes que melhor preenchiam os critérios supracitados.

O grupo controle deste trabalho foi composto por 63 doadores saudáveis do Banco de Sangue do Hemocentro de Ribeirão Preto.

Elisa para pesquisa de anticorpos antiMaxadilan

A técnica de ensaio imunoenzimático não competitivo indireto (Elisa) para pesquisa de anticorpos antiMAX foi padronizada para este trabalho. O peptídeo recombinante produzido em Escherichia coli, MAX, foi gentilmente cedido pelo Prof. Dr. Ethan A. Lerner, da Harvard Medical School, Boston, MA, USA. Resumidamente, realizou-se a sensibilização da placa de microtitulação com 50ul de MAX e adicionaram-se $100 \mu \mathrm{l}$ da amostra de soro diluída (1/50) em PBS-TM (salina tamponada contendo 5\% de leite desnatado). Após período de incubação (duas horas, $37^{\circ} \mathrm{C}$ ) e lavagem, foram adicionados $50 \mu \mathrm{l}$ do conjugado anticorpo-enzima (antilgG humana) seguido de novo período de incubação e lavagem. A seguir, foram adicionados $100 \mu 1$ do substrato (o-fenilenodiamina di-hidrocloreto - OPD-Sigma) e aguardado desenvolvimento de cor, ao abrigo da luz e à temperatura ambiente por 30 minutos. A reação foi interrompida por $\mathrm{H}_{2} \mathrm{SO}_{4} 1 \mathrm{~N}$, e a leitura processada em 492nm (Labsystems Multiskan MS).

\section{Extração de proteínas e de DNA}

A extração de proteínas e de DNA de exemplares de L. longipalpis (controle positivo), obtidos de insetário e cedidos gentilmente pela Dra. Alda Falcão, FioCruz-BH, e de $L$. neivai, coletadas em campo e identificadas pelo Dr. Cláudio Casanova, Superintendência de Controle de Endemias (SUCEN) - Mogi Guaçu, foi realizada pelo método Trizol. Resumidamente, os tecidos são desintegrados por ultrassom até que se dissolvam por completo, utilizando $1 \mathrm{ml}$ de trizol para cada 50-100mg de tecido. 
Adicionam-se $200 \mu \mathrm{L}$ de clorofórmio para cada mililitro de trizol utilizado e homogeneíza-se vigorosamente por 15 segundos. A seguir, incuba-se por 10 minutos em temperatura ambiente e centrifuga-se a $12.000 \mathrm{~g}$, por 14 minutos, a $4^{\circ} \mathrm{C}$. Transfere-se a fase aquosa, que contém o RNA, para outro eppendorf. Ao material restante, adicionam-se $300 \mu \mathrm{L}$ de etanol, em temperatura ambiente por dois ou três minutos e centrifuga-se $2.000 \mathrm{~g}$, por cinco minutos, $4^{\circ} \mathrm{C}$. Remove-se a nova fase aquosa para posterior extração de proteínas, deixando o pellet que contém o DNA. Lava-se o pellet que ficou no tubo com $1 \mathrm{ml}$ de citrato de sódio $0,1 \mathrm{M}$ diluído em etanol $10 \%$. Após homogeneização e centrifugação, despreza-se o sobrenadante e ressuspende-se o pellet com $1,5 \mathrm{ml}$ de etanol $75 \%$. Incuba-se a amostra por 15 minutos em temperatura ambiente e centrifuga-se $\left(2.000 \mathrm{~g}\right.$, cinco minutos, $\left.4^{\circ} \mathrm{C}\right)$. Despreza-se o sobrena-

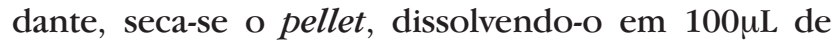
$\mathrm{NaOH}, 8 \mathrm{mM}, \mathrm{pH}=8,4$, obtendo-se assim o DNA. Para a extração de proteínas, adiciona-se $1,5 \mathrm{ml}$ de isopropanol (1:1) à fase líquida do sobrenadante obtido na extração de DNA. Incuba-se (15 minutos) e centrifugase a amostra $\left(12.000 \mathrm{~g}, 10\right.$ minutos, $\left.4^{\circ} \mathrm{C}\right)$. Despreza-se o sobrenadante e lava-se o pellet três vezes com $2 \mathrm{ml}$ da solução de hidrocloreto de guanidina $0,3 \mathrm{M}$ diluído em etanol 95\%. Após a última lavagem, ressuspendese o pellet em $1,5 \mathrm{ml}$ de etanol absoluto, incuba-se (20 minutos, temperatura ambiente) e centrifuga-se $\left(7.500 \mathrm{~g}\right.$, cinco minutos, $\left.4^{\circ} \mathrm{C}\right)$. Despreza-se o sobrenadante, seca-se o pellet, dissolvendo-o em $100 \mu \mathrm{L}$ de SDS $1 \%$, deixando por três minutos a $50^{\circ} \mathrm{C}$, obtendose assim a extração de proteínas.

\section{Eletroforese de proteínas}

A eletroforese de proteínas foi feita em gel de acrilamida 12,5\%, com as amostras de: MAX (16,66ug), proteína extraída de $L$. longipalpis (1,11ug e 0,56ug) e de $L$. neivai $(0,48 \mathrm{ug})$. Após corrida por uma hora e 20 minutos, $100 \mathrm{~V} / 30 \mathrm{~mA}$, foi corado pelo método da prata.

\section{Polymerase Chain Reaction (PCR) para pesquisa de Maxadilan em L. longipalpis e $L$. neivai}

Para a verificação da expressão gênica do MAX em amostras de DNA extraídas de $L$. longipalpis e de L. neivai, utilizou-se a PCR com primers (Invitrogen) que resultam em produtos de 106bp (Figura 1).

A PCR foi realizada com volume final de $25 \mu \mathrm{L}$ contendo buffer $10 \times 2,5 \mu \mathrm{L}$, dntp $2 \mathrm{mMol} 5 \mu \mathrm{L}$, água estéril $10,3 \mu \mathrm{L}$, primer sense $(100 \mathrm{pmol}) 1 \mu \mathrm{L}$, primer antisense $(100 \mathrm{pmol}) 1 \mu \mathrm{L}$ e TaqDNA polimerase $0,2 \mu \mathrm{L}$. A essa mistura foram adicionados $5 \mu \mathrm{L}$ do DNA extraído da amostra a ser amplificada. Utilizou-se um tubo "branco" com água em vez de DNA para controle negativo.

As amostras foram amplificadas em termociclador (Applied Biosystems 9700), obedecendo ao

$\begin{array}{ll}1 & \begin{array}{l}\text { aatcaattgc taaaaaaaa ttacaaatag aactactaca } \\ \text { gatgttctga atttttctt } \\ \text { gatattctt ctcaattgga tgtataaaag aggctattt } \\ \text { gtgctgattt tgttagtcag } \\ \text { tattctgata aactgcaaaa atgaagcaaa tccttttaat } \\ \text { ctctttggtg gtggttcttg } \\ \text { ccgtgttgc cttcagtaag ttcttccttt aggctttcc } \\ \text { ttctcaaaac ttaaagtaat } \\ \text { ttaatgaaat attctttaaa taatctccat tttcttgtag } \\ \text { acgttgctga gggctgtgat } \\ \text { gcaacatgcc aattcgcaa g }\end{array} \\ 301 & \begin{array}{l}\text { caggcgca tcatagcaat } \\ \text { gtttgcaga cttctgtaca aacaactgca acattcacat } \\ \text { caat } \quad \text { ata gtgtcttcaa agaatgtatg aagcagaaga }\end{array} \\ 421 & \begin{array}{l}\text { aaaggaatt tagttcagga } \\ \text { aagtaaaaga ttgaagaaa ttgtagccga ggagagaaag } \\ \text { aaagaaagtc ccataccata } \\ \text { tttgtttgt taattgtaac gaatttccg aaaaataaa } \\ \text { atattatgca ctcaattta }\end{array} \\ 541\end{array}$

Figura 1: Gene do maxadilan

(http://www.ncbi.nlm.nih.gov/entrez/viewer.fcgi?db= nucleotide\&v $\mathrm{al}=159451$ ). Em amarelo, os primers utilizados na PCR, cujo produto final corresponde ao fragmento de $106 \mathrm{pb}$ Os destaques em vermelho e azul mostram os sítios de restrição das enzimas Hha I e Rsa I, respectivamente

seguinte ciclo:

- $94^{\circ} \mathrm{C}$ por $3 \mathrm{~min}$ e $30 \mathrm{seg}$;

- $93^{\circ} \mathrm{C}$ por $30 \mathrm{seg}, 52^{\circ} \mathrm{C}$ por $1 \mathrm{~min}, 72^{\circ} \mathrm{C}$ por $1 \mathrm{~min}-35$ ciclos

- $72^{\circ} \mathrm{C}$ por $10 \mathrm{~min}$, e a seguir por $4^{\circ} \mathrm{C}$ até a próxima fase. Para a identificação das bandas de DNA, foram utilizados $5 \mu \mathrm{L}$ do material amplificado em gel de acrilamida $10 \%$ não desnaturante (150V, por duas horas).

\section{Restrição do fragmento de DNA - RFLP (Restriction Fragment Lenght Polymorphism)}

A partir da seqüência de nucleotídeos do fragmento amplificado de $106 \mathrm{bp}$, utilizaram-se as enzimas de restrição Hha I e Rsa I. Hha I age [?]sobre o sítio de restrição $\mathrm{G}_{-} \mathrm{CG}^{\wedge}{ }^{\wedge} \mathrm{C}$, conferindo dois fragmentos: 30 e 80bp. Já a Rsa I atua no sítio GT|AC resultando em dois fragmentos de 50bp (Figura 1).

Resumidamente, utilizaram-se $1,0 \mu \mathrm{g}$ de DNA do produto da PCR, 1,0 $\mu \mathrm{L}$ do buffer e $5 \mathrm{U}$ da enzima de restrição HhaI ou $10 \mathrm{U}$ de Rsa I, que são completados com água em volume final de $10 \mu \mathrm{L}$, a $37^{\circ} \mathrm{C}$, overnight.

\section{Análise estatística}

Para a análise dos títulos de anticorpos antiMAX, uma vez que os dados obedeceram à curva de normalidade, utilizou-se o teste $t$ de Student.

\section{RESULTADOS}

Pesquisa de antiMAX em soros de pacientes com ITA Anticorpos antiMAX, detectados pelo método 
GráfICO 1: Elisa para pesquisa de anticorpos antiMAX em controles e pacientes com LTA. Títulos de antiMAX (DO - densidade óptica / cut off) em amostras de pacientes com LTA maiores que os do grupo controle $(\mathrm{p}=0,0132)$

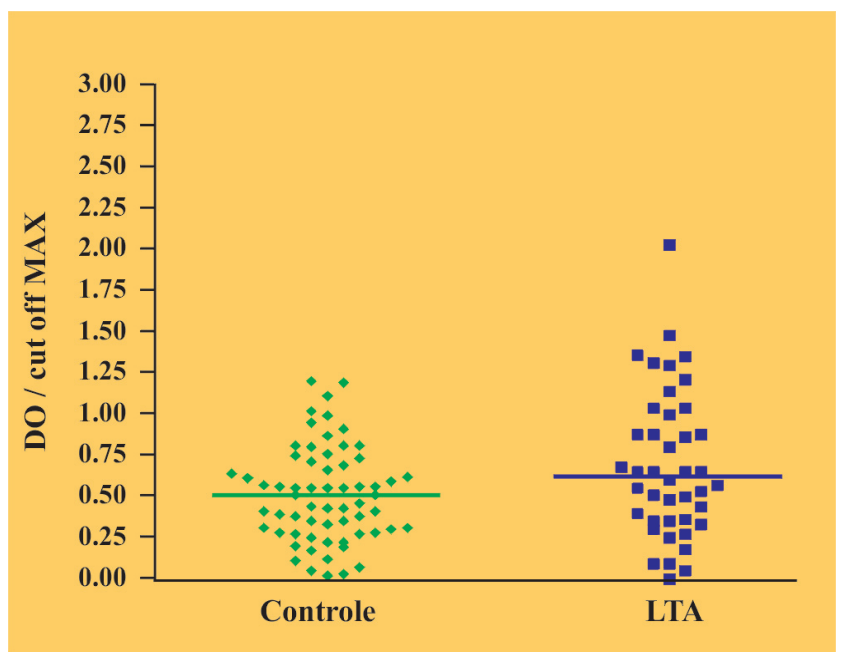

Elisa no soro de pacientes com LTA e controles, foram significativamente maiores no grupo LTA quando comparados aos controles $(p=0,0132)$ (Gráfico 1$)$.

\section{Expressão protéica de MAX em L. neivai}

Várias frações protéicas foram observadas no gel de acrilamida para as amostras de $L$. neivai e $L$. longipalpis. Entre elas, frações de pesos moleculares semelhantes de ambos os vetores compararam-se à fração do MAX (Figura 2).

\section{Expressão gênica de MAX em L. neivai}

Como indica a figura 3, observou-se amplificação de fragmento de 106bp na PCR de L. longipalpis (controle positivo) e de L. neivai, correspondendo ao esperado para fragmento de MAX. A confirmação foi feita por meio de PCR-PFLP. No ensaio em que foi utilizada a enzima Hha I, observaram-se a digestão do fragmento de 106bp e o surgimento de dois novos fragmentos: de 30 e $80 \mathrm{bp}$. No ensaio com a enzima Rsa I, observou-se também a digestão do fragmento de 106bp em dois fragmentos de 50bp.

\section{DISCUSSÃO}

O entendimento da relação parasito/vetor/hospedeiro na leishmaniose é de extrema importância na busca de mecanismos de atuação para o controle da LTA. Resposta imune efetiva é aquela que paralisa a replicação do parasito dentro dos macrófagos e impede a progressão da doença. Isso pode ser obtido pela prévia imunização com parasitos ou antígenos selecionados. No entanto, na LTA, em que se tem um vetor, certamente o flebótomo atua no processo de infecção

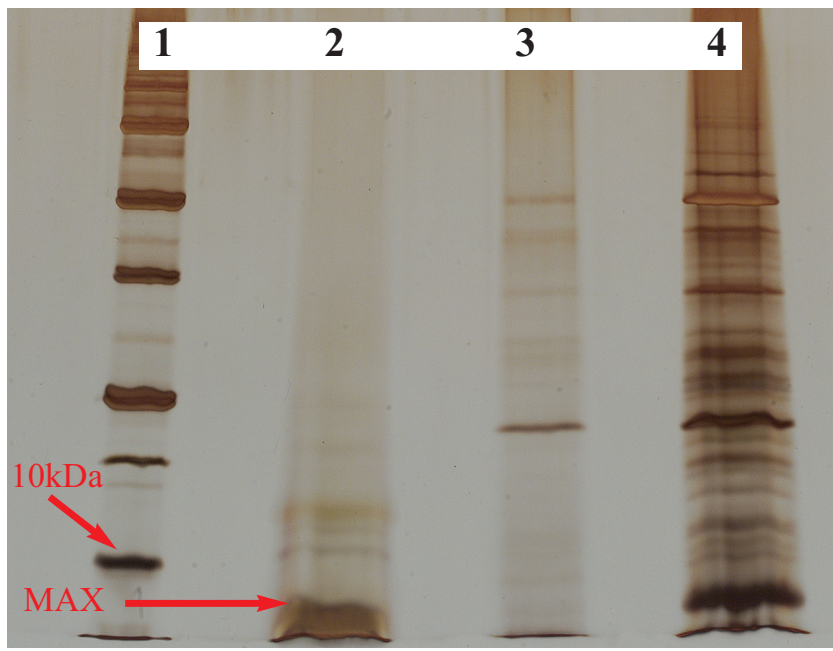

FigurA 2: Gel de acrilamida 12,5\% mostrando eletroforese de proteínas. Colunas: 1 . PM de $10 \mathrm{kDa} ; 2$. MAX (seta).

As frações acima da seta representam dímeros do MAX. 3. Frações protéicas de L. neivai. 4. Frações protéicas de L. longipalpis. As frações de ambos os vetores comparam-se à fração do MAX (seta)

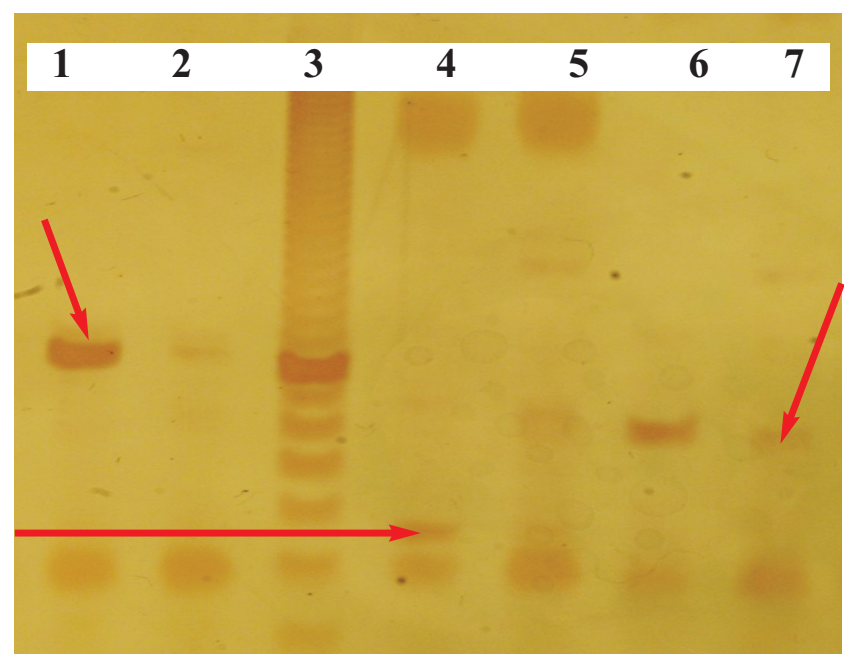

FigurA 3: Gel de acrilamida 10\% mostrando produtos de PCR amplificados para MAX (à esquerda do marcador de PM) e após digestão enzimática (à direita do marcador de PM). Colunas: 1: PCR para MAX de L. longipalpis (seta: 106bp). 2: PCR para MAX de $L$. neivai (106bp). 3. PM de 10bp. 4-5: Produto da PCR digerido com a enzima Rsa I, originando bandas de 55bp (seta), de ambas as amostras, L. longipalpis e $L$. neivai, respectivamente. 6-7: Produto da PCR digerido com a enzima Hha I, originando bandas de $80 \mathrm{bp}$ (seta) e $30 \mathrm{bp}$, de ambas as amostras, L. longipalpis e $L$. neivai, respectivamente.

e promove o estabelecimento da doença. ${ }^{11}$ Inicialmente, os experimentos utilizavam extrato de glândulas salivares de flebótomos, e os resultados sempre apontavam para aumento da infectividade da leishmania na presença da saliva. ${ }^{12,13}$ Lima e Titus ${ }^{14}$ observaram que lisado da glândula salivar de L. longipalpis estimu- 
la, significantemente, a infecção por $L$. braziliensis em camundongos BALB/c e que esses animais produzem duas a três vezes mais interleucina (IL)- 4 se comparados aos animais infectados sem a saliva.

A partir da extração e clonagem de MAX da saliva de L. longipalpis, experimentos foram conduzidos para o melhor entendimento do papel do vetor na infecção e modulação da doença. Morris et al. ${ }^{10}$ demonstraram que MAX pode substituir a saliva e que a multiplicação parasitária em camundongos CBA infectados $\operatorname{com} L$. major e MAX ou L. major e glândula salivar é igual. Submeteram grupos à vacinação prévia com MAX e observaram que as lesões cutâneas em animais vacinados foram de três a cinco vezes menores, com crescimento parasitário reduzido, e que cicatrizavam 50 dias após a infecção, enquanto nos grupos tratados somente com adjuvante ou diluente a cicatrização ainda não havia ocorrido após 65 dias. Para investigar os possíveis mecanismos de proteção, promovida pela vacinação, realizaram dosagens de anticorpos antiMAX no soro por meio do Elisa e detectaram altos títulos. Células de linfonodos regionais, extraídas dos animais tratados, foram estimuladas in vitro com MAX e produziram INF- $\gamma$ e NO (óxido nítrico) em quantidades significativas. Portanto, respostas humoral e celular foram estimuladas em camundongos vacinados.

Rogers e Titus ${ }^{8}$ apresentaram os efeitos do MAX in vitro. Células mononucleares periféricas e monócitos foram obtidos de doadores de sangue saudáveis, cultivados em meios de cultura e incubados com MAX. Posteriormente, foram estimulados com $L$. major, e observaram-se redução da secreção de IFN- $\gamma$ e de IL$12 \mathrm{p} 40$ pelas céluLas mononucleares periféricas e de TNF- $\alpha$ pelos monócitos, e, contrariamente, detectouse aumento na produção de IL-6. Os dados sugeriram que os efeitos imunomodulatórios do MAX sobre células humanas têm importante implicação para o desenvolvimento de vacinas contra a leishmaniose.

$\mathrm{O}$ uso de componentes não parasitários para indução de resposta imune específica contra parasitos, diminuindo a infecção, representa nova e promissora perspectiva na busca de vacinas para doenças em que os patógenos são transmitidos por vetores. A identificação de um componente específico na glândula salivar com atividade imunomodulatória, como, por exemplo, o MAX, é fundamental para o entendimento da interação hospedeiro e vetor no nível molecular. Se esse componente é conservado entre as múltiplas espécies de flebótomos, ter-se-á a possibilidade de desenvolvimento de uma vacina capaz de proteger contra múltiplas espécies de Leishmania pela imunização com uma única proteína do vetor. ${ }^{11}$

É importante salientar que todos os experimentos têm sido realizados com diferentes espécies de leishmania, incluída a responsável pela forma cutânea, enquanto a proteína salivar - MAX - só é descrita em vetor do calazar. Mais recentemente, houve relato de anticorpos antisaliva de $L$. intermedia em pacientes com LTA. ${ }^{15}$

Diante destes resultados - a constatação da presença de antiMAX no soro de pacientes com LTA, chamando a atenção para a presença de antiMAX também em controles - tornou-se imprescindível a pesquisa da expressão de MAX em vetor responsável pela transmissão da LTA na região de estudo. De forma inédita, constatou-se a expressão gênica de MAX em L. neivai, vetor responsável pela transmissão da LTA na região, assim como a expressão de fração protéica correspondente ao MAX.

A presença de anticorpos antiMAX em controles confirma a exposição à picada de flebótomos. Moradores de áreas endêmicas de LTA, mediante a exposição natural à picada de flebótomos, são "vacinados" repetidamente. No entanto, embora seja possível que essa exposição promova redução da gravidade da doença, parece não trazer proteção total. Os resultados deste estudo confirmam isso, pois os pacientes com LTA apresentam títulos de antiMAX maiores do que aqueles dos controles e evoluíram com a manifestação da doença, incluindo a forma mucosa.

Uma vacina eficaz para leishmaniose será aquela que previna o desenvolvimento da doença. Uma redução do processo de infecção, como aquela obtida pela exposição prévia à picada de flebótomos ${ }^{16} \mathrm{ou}$ injeção de MAX, não necessariamente confere imunidade ao parasito ou previne a progressão da doença. ${ }^{10}$ Vetor e patógeno devem ser considerados unidade única integrada no processo infeccioso para o desenvolvimento de vacina segura e eficaz.

\section{CONCLUSÃO}

A população controle, apresentando anticorpos antiMAX, confirma a exposição natural a picadas de flebótomos. Diante dos títulos de anticorpos antiMAX maiores na amostra de LTA, com lesões cutâneas e mucosas em atividade, sugere-se que a exposição prévia e natural à proteína MAX não estaria conferindo proteção imunológica contra a leishmaniose tegumentar, desfavorecendo seu emprego em vacinação.

\section{AGRADECIMENTOS}

Suporte financeiro: Capes; Faepa (Fundação de Apoio ao Ensino, Pesquisa e Assistência). 


\section{REFERÊNCIAS}

1. Davies CR, Kaye P, Croft SL, Sundar S. Leishmaniasis: new approaches to disease control. BMJ. 2003; 326: 377-82.

2. Medeiros ACR. Análise filogenética das espécies de Leishmania implicadas na Leishmaniose Tegumentar Americana em pacientes atendidos no Hospital das Clínicas da Faculdade de Medicina de Ribeirão Preto da Universidade de São Paulo. [tese]. Ribeirão Preto: Universidade de São Paulo; 2002.

3. Lerner EA, Ribeiro JMC, Nelson RJ, Lerner MR. Isolation of maxadilan, a potent vasodilatory peptide from the salivary glands of the sand fly Lutzomyia longipalpis. J Biol. Chem. 1991; 266: 11234-6.

4. Lerner EA, Shoemaker CB. Maxadilan. Cloning and functional expression of the gene encoding this potent vasodilator peptide. J Biol Chem. 1992; 272: 33-7.

5. Jackson TS, Lerner E, Weisbrod RM, Tajima M, Loscalzo J, Keaney JF Jr. Vasodilatory properties of recombinant maxadilan. Am J Physiol. 1996; 271: H924-30.

6. Moro O, Lerner EA. Maxadilan, the vasodilator from sand flies, is a specific pituitary adenylate cyclase activating peptide type I receptor agonist. J Biol Chem. 1997; 272: 966-70,

7. Soares MB, Titus RG, Shoemaker CB, David JR, Bozza $M$. The vasoactive peptide maxadilan from sand fly saliva inhibits TNF-alpha and induces IL-6 by mouse macrophages through interaction with the pituitary adenylate cyclase-activating polypeptide (PACAP) receptor. J Immunol. 1998; 160: 1811-6.

8. Rogers KA, Titus RG. Immunomodulatory effects of maxadilan and Pblebotomus papatasi sand fly salivary gland lysates on human primary in vitro immune responses. Parasit Immunol. 2003; 25: 127-34.

9. Gillespie RD, Mbow ML, Titus RG. The immunomodulatory factors of bloodfeeding arthropod saliva. Parasit Immunol. 2000; 22: 319-31.

10. Morris RV, Shoemaker CB, David JR, Lanzaro GC, Titus
RG. Sandfly maxadilan exacerbates infection with Leishmania major and vaccinating against it protects against $L$. major infection. J Immunol. 2001; 167: 5226-30.

11. Reed SG. Leishmaniasis vaccination: targeting the source of infection. J Exp Med. 2001; 194: F7-9.

12. Titus RG, Ribeiro JM. Salivary gland lysates from the sand fly Lutzomyia longipalpis enhance Leishmania infectivity. Science. 1988; 239: 1306-8.

13. Theodos CM, Ribeiro JM, Titus RG. Analysis of enhancing effect of sand fly saliva on Leishmania infection in mice. Infect Immunol. 1991;59: 1592-8.

14. Lima HC, Titus RG. Effects of sand fly vector saliva on development of cutaneous lesions and the immune response to Leishmania braziliensis in $\mathrm{BALB} / \mathrm{c}$ mice. Infect Immunol. 1996;64: 5442-5.

15. Batista RL, Câmera PO, OliveiraNeto MP, Vilela ML, Costa SM, Pirmez C. Lutzomyia intermedia anti-saliva antibodies in patients living in endemic areas of American tegumentary leishmaniasis in Rio de Janeiro, Brazil. In: ASTMH, 53th Annual Meeting, 2004, Miami, Florida, 2004.

16. Kamhawi S, Belkaid Y, Modi G, Rowton E, Sacks D. Protection against cutaneous leishmaniasis resulting from bites of uninfected sand flies. Science. 2000; 290: 1351-4.

\footnotetext{
ENDEREÇO PARA CORRESPONDÊNCIA: Ana Maria F. Roselino Professora Associada - Faculdade de Medicina de Ribeirão Preto - Divisão de Dermatologia Departamento de Clínica Médica Av. Bandeirantes, 3900 14049-900 - Ribeirão Preto - SP Tel: (16)3633-0236 / 2715 - Fax:(16)3633-6695 E-mail:amfrosel@fmrp.usp.br
} 